\title{
LA ENSEÑANZA DEL DERECHO EN LA UNIVERSIDAD DE LA HABANA A PARTIR DEL SIGLO XX (ETAPA 1901-1958). APROXIMACIONES AL TEMA 1
}

\author{
THE TEACHING OF LAW AT THE UNIVERSITY OF HAVANA FROM THE \\ TWENTIETH CENTURY (STAGE 1901-1958). APPROACHES TO THE TOPIC
}

\author{
YULIESKY AMADOR ECHEVARRIA*
}

RESUMEN: Al hacer un estudio de la Historia de Cuba, encontramos que la enseñanza del Derecho ha estado presente en los distintos centros educacionales de carácter universitario. Cuando hablamos del proceso de formación de los juristas, partimos del criterio que se estructura en torno a la cuestión de qué función deben cumplir en la sociedad. Una interrogante que indudablemente nos hace reflexionar en torno a la funcionalidad de estos y su influencia social. Al ocurrir el proceso de nacionalización de la enseñanza superior posterior al Triunfo revolucionario, comienza a configurarse un nuevo programa de estudios en todos los niveles teniendo como fundamento las nuevas estrategias trazadas por el gobierno que comenzaba a instaurarse .Se buscaba erradicar las deficiencias que se habían venido acumulando y presentando en períodos anteriores donde se enseñó casi de forma general mediante la clase magistral o conferencia del profesor, que podía terminar con la respuesta a preguntas formuladas durante o al terminar ésta y el nivel de exigencia de conocimientos era catalogado como desigual.

PALABRAS CLAVES: Derecho, Cuba, Enseñanza del Derecho, Universidad de La Habana, Métodos de enseñanza

ABSTRACT: When making a study of the History of Cuba, we find that the teaching of Law has been present in the different educational centers of a university nature. When we talk about the process of formation of jurists, we start from the criterion that is structured around the question of what function they should fulfill in society. A question that undoubtedly makes us reflect on the functionality of these and their determining role. When the process of nationalization of higher education after the revolutionary triumph occurred, a new program of studies began to form at all levels, based on the new strategies drawn up by the government that was beginning to establish itself and trying to eradicate the deficiencies that had It has been accumulated and presented in previous periods where it was taught almost in a general way through the teacher's lecture or lecture, which could end with the answer to questions asked during or at the end of this and the level of knowledge requirement was classified as unequal.

KEYWORDS: Law, Cuba, Teaching of Law, University of Havana, Teaching methods

*Licenciado en Derecho. Profesor del Departamento de Ciencias Jurídicas de la Universidad de Artemisa, Cuba. Miembro del Capítulo provincial de Derecho Constitucional y Administrativo, Unión Nacional de Juristas de Cuba, Artemisa, Cuba.

1 El trabajo que se presenta forma parte de las investigaciones que lleva a cabo el autor como parte de su informe final como aspirante al título de Máster en Derecho Constitucional y Administrativo, Facultad de Derecho, Universidad de La Habana. 


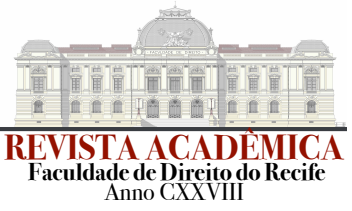

\section{BREVE ESBOZO DE LOS INICIOS DE LA ENSEÑANZA DEL DERECHO}

Hace poco más de cuatro siglos 2 los pueblos de América Latina conocieron las primeras facultades de Derecho, nacientes en el seno de las comunidades religiosas que se dieron a la tarea de formar jóvenes ilustres, sin más pedagogía que el pensamiento medieval de las catedralicias y sin más horizonte que la exigencia y la rigidez del pensamiento escolástico y monárquico. ${ }^{3}$ Esa concepción de alumno, que perduró durante los siglos XII y XIII, continuó aumentando el devenir en el estudio de los cánones, primer nombre dado al estudio jurídico en América (CABRA CAMACHO, 1999). Amplias fueron las bondades de ese sistema pedagógico que erigió la memoria como fundamento de la enseñanza, pero pocos fueron los aciertos que contribuyeron al avance de la ciencia jurídica con dimensiones investigativas.

Flores GARCÍA(1893) ubica a la más antigua escuela de derecho de América en el Calmecac azteca ${ }^{4}$, donde los nobles eran educados por los sacerdotes para el servicio militar, la administración pública y para el delicado desempeño judicial. Ahí se impartía cultura general y varias especialidades, entre ellas la de leyes.

Continúa mencionando el citado autor, que la enseñanza era teórica y práctica, pues una vez que el aspirante a juzgador dominaba la teoría, era trasladado a los tribunales para observar a los jueces y el procedimiento de impartición de justicia.

2 Puede mencionarse: Universidades de San Marcos de Lima (1551), México (1551), San Carlos de Guatemala (1676) y San Cristóbal de Huamanga (1677).

3 Señala Fernández Estrada (2016) que "la enseñanza universitaria del Derecho nació con el método escolástico de estirpe aristotélica, por lo tanto es tradición en la enseñanza jurídica la práctica del discurso unilateral, acrítico, no dialógico, que poco ha cambiado en los planes de estudio de América Latina y el resto del mundo, aún después de la influencia de escuelas de interpretación, concepción y análisis del Derecho, que sobre todo durante el siglo XX trataron de modificar la ciencia del Derecho para convertirla en algo más que un estudio profundo de la norma jurídica."

4 Fue una antigua civilización indígena que habitó zonas de los que hoy conocemos como México, principalmente en el centro y sur del país. En: http://mauricioonline.tripod.com/azteca1.html, consultado el 7-01-16. 


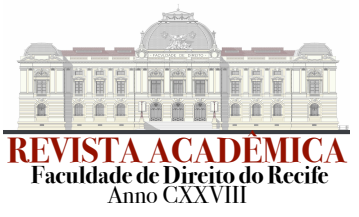

\section{SUCINTA REFERENCIAS A LA EDUCACIÓN EN CUBA DURANTE LA ETAPA COLONIAL. SURGIMIENTO DE LOS ESTUDIOS PROFESIONALES DE DERECHO EN CUBA}

Con el inicio de la conquista y colonización de la isla en el año 1510, los representantes de la corona española comenzaron también el fin de la incipiente civilización que habían encontrado. ${ }^{5}$ Según opinión de CANTÓN NAVARRo (2000, p.18), la influencia de la cultura primitiva en el desarrollo posterior de la sociedad cubana fue sumamente pobre a diferencia del papel que desempeñaron las comunidades indígenas de México, América Central y Sudamérica en la formación de las nacionalidades que hoy habitan en esos territorios.

Las primeras referencias del desarrollo de la educación en Cuba durante la etapa colonial se encuentran en las leyes reales del siglo XVI que ubicaron la enseñanza de la lengua española y la doctrina cristiana a los indios sobrevivientes en el país y a los esclavos procedentes de África. Esta labor se encomendó, en lo fundamental, a los eclesiásticos y doctrineros. Constituye así la educación, desde sus inicios, un proceso social complejo con un profundo matiz histórico y clasista, gracias al cual tiene lugar la transmisión y la aprobación del acervo cultural acrisolado por el ser humano (NARANJO SAAVEDRA \& ZALDÍVAR, 2013).

A partir de la segunda mitad del siglo XVI se fundaron en Cuba los primeros centros de enseñanza. Las fuentes informativas disponibles permiten aseverar que hubo una intervención amplia de franciscanos y dominicos en esas actividades, y de cierto número de jesuitas. Se estima a Miguel VELÁSQUEZ como el primer maestro cubano, pues conjugó sus funciones de sacerdote con las de enseñar entre los años 1540-1544. Se dice que estas acciones fueron los exiguos resplandores que recibió la colonia de un ciclo de gran progreso cultural en España.

\footnotetext{
5 Refiere Mesa CASTILlo (2009, p. 271) que "Cuba, sin dudas, no estaba habitada por naturales que pertenecían a una organización social y política desarrollada como otras culturas precolombinas de América; al parecer, los aborígenes no rebasaban el estadio de la barbarie y se comportaban como miembros de verdaderas familias punalúas, según el concepto formulado por MORGAN y ENGELS".
} 


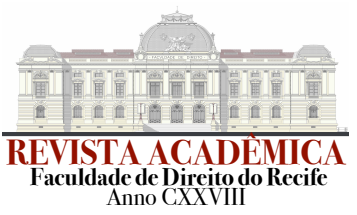

Puede afirmarse que los estudios profesionales de Derecho en Cuba surgen con la fundación de la Universidad de La Habana en 1728. Universidad, que citando a GUANCHE, "lleva inscritos la marca de fuego de una era, el trazo de una cultura, la coherencia de sentido para los habitantes de una nación” (GUANCHE, 2001, p.31). Desde su fundación esta institución contó con una facultad de Derecho, que adquirió diferentes nombres en correspondencia con las corrientes pedagógicas del momento (PÉREZ VÉLIZ, 2012, p.29).

\section{ALGUNAS CONSIDERACIONES SOBRE EL ESTADO DE LA EDUCACIÓN SUPERIOR A INICIOS DEL SIGLO XX.}

La vida republicana de Cuba inicia con una existencia marcada por el desenlace del frustrado proceso de lucha revolucionaria del siglo XIX (ARMAS; TORRES CUEVAS \& BALLESTER, 1964, p. 284). La situación social, cultural y educacional, tras casi cuatro siglos de dominación española se tornaba aterradora y las dos terceras partes de la población de la Isla resultaban analfabetas (ARMAS; TORRES CUEVAS \& BALLESTER, 1964, p. 254). Según palabras de VARONA (1901, p. 32), en la mayor parte del país la ignorancia era casi absoluta. Sólo el 0,5 \% de los habitantes de la Isla habían obtenido grados universitarios, mientras que la matrícula giraba sobre unos mil alumnos en la única Universidad existente, trayendo como consecuencia que la enseñanza en la educación superior fuera considerada angustiosa. Este deterioro y abandono fue calificado como un legado del colonialismo español.

Era de suponer que con la terminación del régimen colonial se produjera un vuelco en la educación cubana y se convirtiera en realidad la aspiración martiana según la cual: “Como quien se quita un manto y se pone otro es necesario poner de lado la Universidad antigua y alzar la nueva" (MARTÍ, 1964, P.299). Sin embargo, para ese entonces, la única casa de estudios superiores afrontaba los peligros provenientes de la ignorancia generalizada y de la pretensión de los Estados Unidos de «americanizar» la Isla(GUANCHE, 2001, p. 33), pues la antigua Universidad Literaria y Real que había heredado los principios primigenios y los 


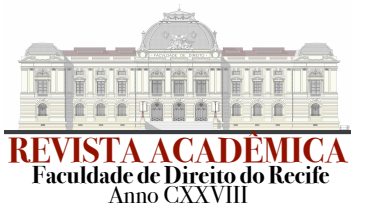

planes de estudios de la Real y Pontificia Universidad de San Gerónimo, se encontraba conmovida profundamente con las dos grandes guerras libertarias del siglo XIX (GUANCHE, 2001, p. 33). Cuando se consulta la Memoria -Anuario de la Universidad de La Habana correspondiente al curso 1898-1899, los adjetivos utilizados para catalogarla, eran de crítica y angustiosa. 6

A pesar de esto, citando a CARRERAS CUEVAS, "La Universidad, pese a estar situada en un derruido convento, conservaba el prestigio espiritual de no haber cerrado jamás sus puertas y de formar en sus aulas el patriciado heroico surgido con los protomártires del 27 de noviembre de 1871, consolidado con la presencia impar de Ignacio Eduardo DE LAS Mercedes Agramonte y LoynaZ —el jurista más emérito que hemos tenido-, con la figura señera del Padre de la Patria Carlos Manuel DE CÉSPEDES Y DEL CASTILlo, con la talla de los hermanos SANGUILY, de los ZAMBRANA, y con aquella legión de hombres genuinamente cubanos, comprometidos con el destino de su patria." 7

"Inmersa en su medio social, -plantean DE ARMAS y TORRES-CUEVAS en su ya citada obra- la Universidad no podía escapar al proceso de neocolonización, ni al proceso de paulatina descomposición política de las administraciones republicanas. Un oscuro y tranquilo período se desarrollaría ahora hasta la década de los años veinte, con el predominio- dentro del Claustro de profesores y del gobierno universitario- de los elementos más conservadores" (ARMAS; TORRES CUEVAS \& BALLESTER, 1984, p. 284)

\section{LA ENSEÑANZA DEL DERECHO EN CUBA DURANTE LA ETAPA NEOCOLONIAL.}

La Orden Militar No. 212, de fecha 4 de noviembre de 1899, dictada dos años antes del inicio del Siglo, promulga un nuevo Plan de estudios para la Universidad, el cual, a decir

\footnotetext{
6 Más información ver: Universidad de La Habana. Memoria-Anuario correspondiente al curso académico de 1898 a 1899, Imprenta M. Rui y Comps., La Habana, 1900, p. VII.

${ }^{7}$ Más información ver: Universidad de La Habana. Memoria-Anuario correspondiente al curso académico de 1898 a 1899, Imprenta M. Rui y Comps., La Habana, 1900, p. VII..
} 


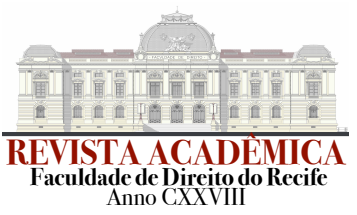

de Matilla CORREA, nos coloca en la Modernidad pedagógica docente. ${ }^{8}$ Plan LANUZA era el nombre por el cual se le conocía haciendo alusión al Secretario de Justicia e Instrucción Pública y máxima autoridad en materia de enseñanza, el Doctor José Antonio GonZÁlEz LANUZA, quien es considerado como su creador.

Plantean DE ARMAS y TORRES-CuEvas y BALLESTER (1984, p. 259-260) que este Plan no respondía a las necesidades de un país que recién decía adiós a una guerra de exterminio, y la única diferencia con su antecesor consistía en ampliar el número de cátedras de las cinco facultades que tradicionalmente constituían la Universidad, así como mantener el antiguo sistema de grados de Licenciado y Doctor en todas las facultades. Como modificación sólo introdujo la supresión del período de estudios del Doctorado.

El período de vigencia de esta Orden fue efímero producto de la sustitución del General John BRooK por el General Leonard WoOD, quien separó las Carteras de Justicia e Instrucción Pública, nombrando para la última a Enrique JOSÉ VARONA9, cuyas ideas estuvieron presentes en la Orden 266. Citando al propio Varona, en la Universidad "todo era añejo e inservible, las aulas eran pobres, los laboratorios estaban desprovistos de material y mal acondicionados, y no había biblioteca, pues la de la Universidad no podía ser más vetusta y menos surtida de obras indispensables para el aprendizaje de los alumnos" (DIHIGO Y MESTRE, 1930, P. 31)

Formar profesionales que en la práctica resolviesen los problemas del país fue lo más esencial recogido en este nuevo Plan que suprimía la distinción entre la Licenciatura y el Doctorado, permaneciendo sólo este último. Si bien este Plan tuvo mayor repercusión desde el

8MATILla Correa, Andry: "Breve tracto histórico de la Enseñanza del Derecho Constitucional en Cuba", anotaciones tomadas por el autor de la presente investigación en el Taller sobre la enseñanza del Derecho Constitucional, celebrado en el Salón de Historia de la Facultad de Derecho de la Universidad de La Habana, el 24 de mayo de 2016.

9 Monseñor Carlos Manuel DE CÉSPEDES al referirse a él, lo consideraba "un hombre noble y bueno, ídolo de la juventud cubana de la época, amigo personal de José MARTí, pero anticlerical, aunque muy respetuoso. (En: BÁEZ, Luis y Pedro DE LA Hoz: Monseñor Carlos Manuel se confiesa, Casa Editora Abril, 2015, p. 90.) Por su parte Raúl ROA GARCÍA afirma que "fue uno de los más extraordinarios escritores de nuestra lengua" y que "a él se debió la transformación de la Universidad colonial en una Universidad teóricamente en condiciones de escalar la altura de la época". (En: Palabras pronunciadas por el Dr. Raúl RoA GARCíA en el acto de su investidura como Profesor de Mérito de la Universidad de La Habana el día 23 de abril de 1977). 


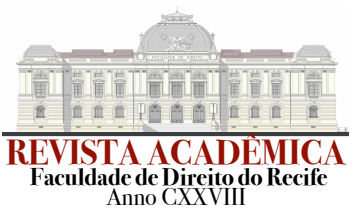

punto de vista de la organización de la Enseñanza del Derecho, siguió prácticamente lo que LANUZA había establecido. ${ }^{10}$

Cabe señalar que aunque el Plan VARONA ${ }^{11}$ obedecía a la más profunda visión teórica de su época, criticando la enseñanza verbalista y retórica, para convertirse en objetiva y científica (VARONA, 1910, p. 10), fue el centro de varios ataques que tuvieron como eje la notable reducción que se hacía del número de profesores y la supresión de los programas de las asignaturas bajo el basamento de que estos convertían en mecánico el proceso de instrucción y limitaban la libertad del profesor a la hora de impartir docencia.

Para ese entonces, la Facultad de Derecho contaba con las escuelas de Derecho Civil, Público y Notariado ${ }^{12}$. Esta organización se mantuvo sin grandes cambios durante veinte años.

En el año 1925 se hace efectiva la Ley de 2 de julio, que según HERNÁNDEZ FIGUEROA (1925, p. 25) merecía aplausos más por lo que permitía hacer, que por lo que en realidad hacía. Esta Ley agrega la asignatura Legislación Hipotecaria y hace extensiva a toda la carrera Economía Política, que ya se impartía en la Escuela de Derecho Público. Introduce además el sistema de Seminarios ${ }^{13}$, lo que permitía que "en vez de un actor, el maestro, y muchos

\footnotetext{
${ }^{10}$ Matilla Correa, Andry: "Breve tracto histórico de la Enseñanza del Derecho Constitucional en Cuba", anotaciones tomadas por el autor de la presente investigación en el Taller sobre la enseñanza del Derecho Constitucional, celebrado en el Salón de Historia de la Facultad de Derecho de la Universidad de La Habana, el 24 de mayo de 2016
}

${ }^{11}$ Texto del Plan de Estudios tomado de La Orden Militar 266 de 30 de junio de 1900, publicada en la Gaceta de 5 de julio de 1900.

12 Los estudios de Derecho establecidos por la Orden 266 de 1900 eran los siguientes: Escuela de Derecho Civil: Derecho romano, Derecho civil, Derecho penal, Derecho procesal, Derecho mercantil y Redacción de instrumentos públicos. Estos estudios era necesario que se completaran con los de Latín, Historia Moderna, Psicología, Filosofía moral, Sociología, Economía Política y Antropología. Una vez aprobado el ejercicio de grado, se concedía el título de Doctor en Derecho Civil. Escuela de Derecho Público: Economía Política, Hacienda pública, Derecho Administrativo, Derecho político y Derecho Internacional. Estos estudios eran completados con los de Historia Moderna, Psicología, Filosofía moral, Sociología, Derecho civil y Derecho penal. El título que se recibía una vez realizado el ejercicio de grado era el de Doctor en Derecho Público. Escuela del Notariado: No tenía asignaturas propias. Estas eran estudiadas en las escuelas anteriores y se exigía aprobar: Derecho civil, Derecho penal, Derecho procesal, Derecho mercantil, Derecho administrativo y Redacción de instrumentos públicos. Otro de los requerimientos era la acreditación de un año de práctica y realizar el ejercicio de grado que permitía la investidura como Notario. (Texto del Plan de Estudios tomado de $\mathrm{La}$ Orden Militar 266 de 30 de junio de 1900, publicada en la Gaceta de 5 de julio de 1900)

${ }_{13}$ Pueden consultarse estas modificaciones en el Texto de la Ley de 2 de julio de 1925 que establece el nuevo Plan de Estudios. 


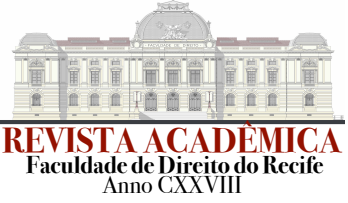

espectadores, los alumnos, ahora todos son, al propio tiempo, actores y espectadores" (FIGUEROA, 1925, p. 25).

En mayo de 1927, el Directorio deja recogidos en una comunicación dirigida al Consejo Universitario nueve puntos que resumían sus posiciones y demandas. El punto número nueve establecía que "se satisfaga el deseo de los alumnos de Derecho que se discuta por las cátedras mediante conferencias públicas todos los problemas de carácter nacional pasados, presentes y futuros" (GONYÁLEZ CARBAJAL, 1974, p. 211). Es en este año cuando se inaugura el nuevo edificio de la Escuela de Derecho "José A. González Lanuza", hoy Ignacio Agramonte.

A pesar del contenido político de muchos de los sucesos que se daban en la Universidad de La Habana, los últimos años de la década del veinte también incluyeron cambios para la enseñanza del Derecho. Una de las más importantes modificaciones introducidas fue la Reforma de la Facultad de Derecho, efectuada por decreto presidencial número 1364. ${ }^{14}$.

La Facultad reorganizó su sistema de estudio con el objetivo de que las asignaturas se impartieran en cursos más breves y que la enseñanza fuera más intensa. Planteaba además un cambio de nombre para la Facultad, la cual comenzaría a denominarse Facultad de Derecho y de Ciencias Sociales, dividida a su vez en la escuela de Derecho que comprendería los estudios propios de las ramas del derecho privado, y la Escuela de Ciencias Políticas, Sociales y Económicas como sustituta de la anterior Escuela de Derecho Público.

El Derecho civil y el Público, carreras fundamentales del antiguo plan no quedaban eliminadas con estos cambios, sino que se les cambiaba la denominación y parte de su contenido. Cabe señalar que se crean otras como Procurador Público y de Certificado de Estudios Administrativos. Otro de los puntos que establecía era el restablecimiento de la diferencia entre Licenciado y Doctor. Es preciso recordar que ya la Orden Militar No. 212, de fecha 4 de noviembre de 1899, conocida como Plan LANUZA, mantenía el antiguo sistema de grados de Licenciado y Doctor en todas las facultades.

14 Gaceta Oficial de 17 de septiembre de 1928. (Cuando se consulta el libro: La Universidad de La Habana (1728-1928) de Juan M. DiHIGO Y MESTRE, la fecha que menciona cuando hace referencia al Decreto 1364 es 10 de agosto de 1928. ) 


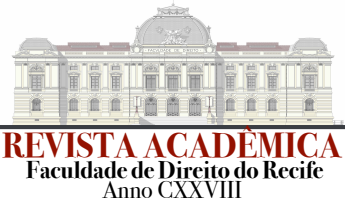

A lo anterior se suma que el antiguo Seminario Diplomático y Consular, que existía anexo a la Facultad de Derecho, se incorporó a esta, refundiéndose sus estudios en los de la Escuela de Ciencias Políticas, Sociales y Económicas. En la Facultad de Derecho ocurre una sustitución del título de Licenciado por el de Abogado, y anexo a ella se crea la Escuela Superior de Comercio, aunque su funcionamiento era independiente. Se restablecen además los cursos preparatorios con el fin de que los estudiantes al enfrentarse a las asignaturas propias de la carrera, posean una preparación que supere a la obtenida en el bachillerato (DIHIGO Y MESTRE, 1930, p.47).

HART DÁvAlos afirma que desde finales de la década del 30 y hasta comienzos de la del 50, la politiquería pseudorrevolucionaria influenció con gran fuerza en las decisiones dentro de la universidad. Refiere MATILla CORREA que :

desde nuestro punto de vista, ese será el tiempo de mayor desarrollo científico del Derecho Administrativo en Cuba. Durante el que desarrollan su obra fundamental autores como Julián Modesto RUIZ Y GóMEZ, quien en 1935 da a la luz un completo texto sobre el régimen jurídico del personal de la Administración Pública, y que para nosotros es, quizás, el texto más completo sobre esa materia que para ese tiempo existía en lengua hispana; Rafael SANTOS JIMÉNEZ Y FERNÁNDEZ, quien en 1945 publicó un magnífico Tratado de Derecho Electoral; y Antonio LANCís Y SÁNCHEZ, autor del más internacional y conocido de los manuales cubanos escritos, al menos hasta los últimos dos decenios del siglo XX. Estos tres autores van a reunir una importante obra - de corte general, en especial - en materia de Derecho Administrativo, derivada sobre todo de su experiencia docente en las aulas universitarias.(MATILLA CORREA, 2012, p. 407)

Al declararse la huelga revolucionaria en marzo de 1935, aparecen nuevas dificultades ${ }^{15}$ que provocan otra vez la clausura de la Universidad, la que vuelve a reintegrarse a la vida normal en febrero de 1937. Posterior a estos años la Facultad de Derecho tuvo que aclimatar sus programas, planes de estudios y estructuras al sistema de justicia norteamericano, si bien siempre predominó el modo Romano - francés- germánico en el Derecho cubano, se escriben nuevos estatutos quedando dividida la Facultad de Derecho en

15 Después de haber despojado a la Universidad de todos sus derechos y de colocarla bajo la dependencia de la Secretaría de Educación por el decreto de 2 de julio de 1935, se dictó el decreto-ley No. 118, de 7 de agosto del mismo año, por el cual se creó una Comisión Reorganizadora Universitaria, compuesta de dieciocho miembros, doce propietarios y seis suplentes, quienes serían designados por el Presiente provisional. La principal función de este organismo era "...que gozando de plena autonomía en el desenvolvimiento de sus funciones, resolviera con entera libertad los problemas universitarios, sustrayéndolos de la esfera de atracción político-social...", según reza en su segundo por cuanto. Todo lo cual quería decir que la Universidad debía encerrarse entre sus paredes como si fuera un organismo aparte de la vida nacional. (En: PICHARDO PIÑALs: Hortensia: Documentos para la Historia de Cuba V, Editorial Pueblo y Educación, La Habana, 2001, p. 60). 


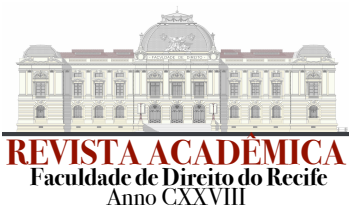

dos facultades: Facultad de Derecho, propiamente dicha, donde se graduaban los Doctores en Derecho Civil y la Facultad de Ciencias Sociales y Derecho Público, que hoy es la Facultad de Historia, donde se graduaban de Derecho Público, estableciéndose un plan de cinco años de estudios con fuerte influencia del positivismo italiano y alemán en algunas disciplinas. 16

Puede afirmarse, siguiendo el criterio de MATILla CORREA, que existían dos Facultades a los efectos de la vinculación jurídica en esa época aun cuando esta haya tenido el nombre de Facultad de Derecho. ${ }^{17}$

La Ley Docente del 8 de enero del propio año al restablecer el funcionamiento de todos los centros docentes, ratifica la autonomía universitaria, que alcanza rango constitucional al ser recogida por la Constitución de 1940 en su artículo 5318y en la Disposición transitoria al Título V, Sección Segunda, en la cual se detallaba pormenores económicos acerca de esta institución. Los nuevos Estatutos elaborados y promulgados como consecuencia de la Ley Docente modificaron totalmente los Planes de Estudio vigentes y la estructura de su organización.

Todas las enseñanzas estarían regidas por el principio de libertad de cátedra y la Universidad se estructuraría por órganos de representación, elegidos democráticamente. Sin embargo, refiere BISBÉ que "la vida académica sufría una desmoralización cuyas raíces hay

\footnotetext{
16Primer año: Historia de Cuba, Historia contemporánea. Teoría general del Estado, Derecho romano (I), Introducción general al estudio del Derecho, Sociología y Antropología jurídica. Segundo año: Derecho constitucional, Derecho romano (II), Derecho administrativo (I), Derecho civil (parte general y persona). Economía Política (I), Derecho penal (I), Derecho civil (propiedad y derechos reales) y Derecho fiscal. Tercer año: Derecho civil (familia), Derecho procesal (I), Derecho mercantil (I), Derecho penal (II), Derecho administrativo (II), Legislación obrera. Legislación fiscal, Legislación de propiedad industrial. Economía Política (II). Cuarto año: Derecho civil (contratos), Derecho civil (sucesiones). Derecho mercantil (II), Derecho hipotecario. Derecho internacional privado, Derecho procesal criminal. Seminario de Ley y práctica notarial. Seminario de procesos civiles generales. Seminario de procesos civiles y criminales y Seminario de registro de la propiedad (los seminarios eran los únicos que tenían una duración de dos horas semanales). Quinto año: Filosofía del Derecho. Esta asignatura fue incluida en el curso 1940-1941 que fue cuando se extendió la carrera a cinco años lectivos. También se incluyó la asignatura de Legislación fiscal en tercer año. (Puede consultarse: CARRERA Justi, Francisco: La Reforma del Plan de Estudios para el curso académico de 1937 a 1938, la necesidad y la urgencia de su sanción. Facultad de Ciencias Sociales y de Derecho Diplomático y Consular, La Habana, Imprenta Cuba Intelectual, 1937; Plan de Estudios, Facultad de Ciencias Sociales y Derecho Público, vigente desde el curso 1940-1941, La Habana, 1940; Plan de Estudios, Facultad de Ciencias Sociales y Derecho Público, La Habana, 1941.)
}

17Matilla CorreA, Andry: "Breve tracto histórico de la Enseñanza del Derecho Constitucional en Cuba", anotaciones tomadas por el autor de la presente investigación en el Taller sobre la enseñanza del Derecho Constitucional, celebrado en el Salón de Historia de la Facultad de Derecho de la Universidad de La Habana, el 24 de mayo de 2016.

18 Constitución de 1940: Tomado de: Nueva Constitución de la República de Cuba. Acordada por la Convención Constituyente de 1940, Editorial Luz-Hilo, La Habana, 1940. 


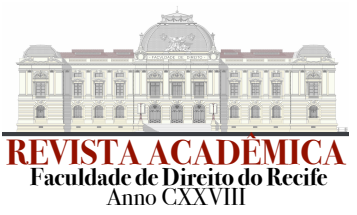

que buscarlas no solamente en los estudiantes que persiguen la línea académica fácil, sino principalmente en aquellos profesores que, faltos de autoridad moral, la facilitan"(BISBÉ, 1940).

\subsection{TRATAMIENTO Y ENSEÑANZA DE LAS ASIGNATURAS DE CORTE HISTÓRICO}

Las asignaturas de contenido histórico comenzaron a tener una animosa presencia desde 1940, teniendo presente, como bien afirmó FERNÁNDEZ BulTÉ, que "en su proceso de formación como hombre, en interacción con la vida material y espiritual circundante, el hombre y cada una de sus generaciones debe repasar y reevaluar el camino que ha conducido a la humanidad hasta su presente" (BULTÉ, 1999, p. 5).

Según criterio de PÉREZ VÉLIZ en su libro Aproximación a la didáctica del Derecho, se caracterizaban por el formalismo y la descripción hechológica, cronológica y geográfica de los procesos legislativos, sin revelar siquiera la relación de estos con los procesos económicos, sociales y políticos. No se estudiaban las leyes del desarrollo histórico-social del mundo y su reflejo en Cuba.

Las asignaturas que no eran de contenido propiamente histórico no abordaban con una adecuada concepción evolutiva las instituciones de Derecho que a ellas correspondían. Robert W. GORDON afirma que el peligroso enfoque de esto radica en que ponía de relieve los riesgos subversivos que dicho historicismo ejercía sobre la racionalidad y la legitimidad del orden, desde negar que la realidad histórica fuera realmente relevante para el proyecto racionalizador del Derecho hasta la de resignarse a aceptar la contingencia histórica del Derecho, pero sin estudiarla, por considerar que se trataba de una realidad paralela y omisible en dicho proceso de racionalización.

La estrategia más usada, según criterio del propio autor, había sido la de aceptar la realidad histórica del Derecho, aunque simplificándola o Instrumentalizándola para justificar el propio orden jurídico presente. ${ }^{19}$

${ }^{19}$ Más información ver W. GORDON, Robert: “Historicism in Legal Scholarship”, en The Yale Law Journal. 


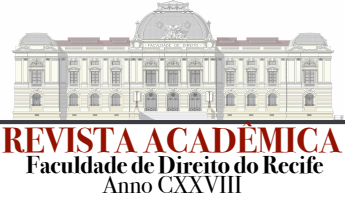

\subsection{UTILIZACIÓN DE MÉTODOS Y MEDIOS PARA LA ENSEÑANZA DEL DERECHO}

Señala el ya citado autor PÉREZ VÉLIZ que la enseñanza se centraba en el profesor, el cual explicaba la asignatura de manera lineal y verbalista, sin mucha apoyatura en medios de enseñanza, ni siquiera en tradicionales como la pizarra. Cabe señalar que los medios ayudan de manera fundamental al cumplimiento de los objetivos y a que el estudiante logre el aprendizaje deseado. Permiten, además, hacer más comprensivos los contenidos de cada asignatura jurídica, y lograr mayor eficacia en el proceso de asimilación del conocimiento por parte de los estudiantes, creando las condiciones necesarias para el desarrollo de capacidades, hábitos, habilidades y la formación de convicciones.

En estos años el alumno debía memorizar los contenidos expuestos por el profesor, y reflejarlo en las evaluaciones de fin de curso, lo más fiel posible a como los había recibido. Según palabras de HERNÁNDEZ FIGUEROA“no se preocupa penetrar en la entraña de la norma, descubrir su sentido y su poder, fijando el principio que la informa y le da vida y aliento, sino que se resignan a conocer sus palabras y a retenerlas para aportarlas como el máximo de la sabiduría universitaria en la prueba decisiva del examen" (FIGUEROA, 1925, p.8). El propio autor considera esta práctica "intolerable y torpe" (FIGUEROA, 1925, p. 20), pues vulnera la iniciativa del alumno y hace que en la mayoría de los casos se ajuste sólo al criterio del profesor, que no siempre viene provisto de originalidad.

Realizando un análisis de este método que tenía como actor protagónico a la memoria, el autor considera que el estudiante, más que memorizar, debe estar dispuesto a comprender, entender y dialogar sobre los conceptos, tratando de encontrar en ellos un significado mucho más inteligente y no olvidando que en la ciencia jurídica, el método se manifiesta por medio de las formas de investigación y disposición del material de estudio, con una solución de tareas concretas de carácter teórico, práctico, cognoscitivo y pedagógico. La manera de seleccionar las tareas asignadas se determina en forma de reglas generales; el método viene a ser una teoría práctica, dirigida a la propia actividad de la investigación jurídica, a lo que es lo mismo, la teoría verificada por la práctica y utilizada como principio regulador del conocimiento. 


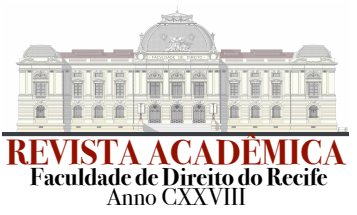

Teniendo en cuenta que el desarrollo de la ciencia jurídica lleva al surgimiento de nuevas y diversas ramas y disciplinas, no puede obviarse que el derecho es activo, está en constante evolución, es por eso que la enseñanza del Derecho debe tener una función social, y entre los aspectos fundamentales de esa función social, se encuentra transmitir la experiencia acumulada por las generaciones precedentes, pero ajustándose a requerimientos de carácter pedagógico. En el período cuestión de análisis, las clases se impartían en los tradicionales teatros o aulas de conferencia, con podios elevados para los docentes, los cuales gozaban de una autoridad indiscutida y en ocasiones abusiva (VÉLIZ, 2012, p. 31).

Siguiendo la opinión de WiTKER (2008, p. 130), esto se considera un método arbitrario, pues una metodología que busca formar juristas activos, críticos y sensibilizados de los problemas colectivos, requiere de técnicas dinámicas y de una dialéctica creadora y moderna. El ya citado HERnÁndez FigueroA al referirse a esto deja caro que se vuelve "frágil como todo lo que no entra en la mente por la inteligencia; efímero, como todo lo que es producto de un esfuerzo de memoria, desarrollado bajo el íncubo del examen; todo ese aprendizaje se pierde a medida que el tiempo aleja al estudiante de la prueba realizada" (FIGUEROA, 1925, p. 8). El índice de fracaso escolar presente en esta etapa era muy alto, siendo suavizado en muchos casos por la posición económica y política del estudiante o su familia.

Tomando en consideración que el Método en el campo de la enseñanza es el conjunto de procedimientos adecuados para lograr un fin específico y en el área de formación del jurista, el método es el camino que elegimos para llegar a formar un profesional crítico, creador y útil a la sociedad en que sirve, a formar un científico del Derecho y jurista abierto al cambio social y al desarrollo, podemos decir que en sentido general, los métodos pedagógicos utilizados en esta etapa se consideraban tradicionalistas, lo cual no propiciaba el desarrollo del pensamiento histórico-lógico.

A esto se suma que la enseñanza práctica era un aspecto descuidado, característica esta que según FIX-ZAMUNDiO (1995, p. 5) estaba presente en toda la región, predominando de manera abrumadora la exposición de los conocimientos doctrinales, que producto de su rigidez y formalismo era considerada dogmática. Según el propio autor la teoría sin la práctica se transforma en una simple especulación y a su vez la práctica desvinculada de la doctrina se 


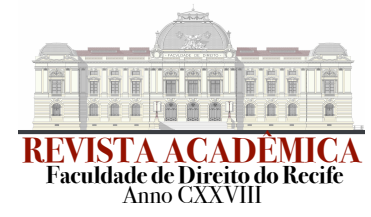

traduce en una serie de datos pragmáticos carentes de sistematización, que impiden a los alumnos una formación sólida que les permita una actitud crítica hacia los ordenamientos establecidos, limitándolos a la posibilidad de evolución y de cambio.

Siguiendo el criterio de NOVOA MONREAL, debe abatirse la enseñanza formalista y rígida del derecho. Apostar por una enseñanza realmente renovada en este período, no suponía adoptar esquemas de enseñanza informales y débiles, sino el diseño de opciones suficientemente formales y flexibles que permitiesen robustecer la enseñanza jurídica, la cual implica "una actitud general que debe inspirar a todo docente del derecho: postura crítica frente a un sistema legal y a una teoría jurídica retrasados (MONREAL, 1981, p.62-64). Es decir, se debe excluir (...) todas aquellas elaboraciones míticas destinadas, en el fondo a preservar la manutención del orden social existente y que significan concepciones jurídicas extra científicas, ajenas a la realidad del derecho (...)”. (MONREAL, 1981, p. 70-72)

Hay que tener presente que los métodos a utilizar, deben determinarse según resulten para lograr los objetivos de la enseñanza, y los medios son los instrumentos con que se cuenta desde el punto de vista teórico, como un sentido práctico, atendiendo sobre todo a la realidad del trabajo docente (BETANCOURT, 2009). Cuando se valora la enseñanza de las ciencias jurídicas en el período, se evidencia que el mayor interés recae en los contenidos a impartir, no sucediendo lo mismo con los métodos y medios que en la mayoría de los casos no se toman en consideración.

\section{ORGANIZACIÓN DE LA ESCUELA DE DERECHO (1952-1958). REFERENCIAAL VÍNCULO DEL MOVIMIENTO ESTUDIANTIL REVOLUCIONARIO CON LOS COMBATES CONTRA LA DICTADURA BATISTIANA}

Resulta de inmenso interés tener presente que la historia de la Universidad de La Habana de 1952 a 1958 se entrelaza con los combates contra la dictadura batistiana. Durante este período el movimiento estudiantil revolucionario se hace predominante dentro de la institución, y determina en muchos casos las características y la marcha de los 


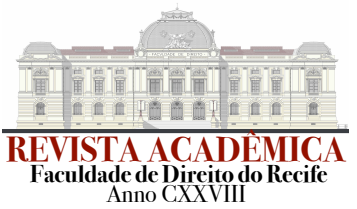

acontecimientos dentro de sus muros (ARMAS; TORRES CUEVAS \& BALLESTER, 1964, P.613)

Para ese entonces la Escuela de Derecho estaba organizada por cátedras, identificada por letras ${ }^{20}$. Anexa a ésta, existía también una Escuela Práctica de Derecho donde se impartían los Seminarios de Legislación y Práctica Notarial, Procedimientos Civiles Generales, Procedimientos Civiles y Criminales, y de Registro de Propiedad. Además existía la Escuela de Ciencias Sociales y de Derecho Diplomático y Consular que conferían los títulos de Licenciado en Derecho Diplomático y Consular, Licenciado en Derecho Administrativo y Doctor en Ciencias Políticas, Sociales y Económicas. La heterogeneidad clasista era una característica que ya se hacía notable tanto en alumnos como en profesores.

FERNÁNDEZ Bulté (2005, p. 314) planteó que este período fue ocupado esencialmente, en el espacio iusfilosófico, por la influencia absorbente de la que primero se llamó Escuela de Viena y posteriormente, Escuela Normativista, que surgiera bajo la inteligencia y la obra del maestro vienés Hans KELSEN, como escuela o doctrina de la Teoría pura del Derecho (BULTÉ, 2005, p. 314). Según criterio del propio autor "a KELSEN lo seguían casi todos, aunque apenas lo habían estudiado una docena de investigadores, y lo entendían no más de cinco grandes juristas" (BULTÉ, 2011, p. 36). La vertiente más amplia del positivismo jurídico, centrada en la línea de León DUGUIT también ejerció influencia en el pensamiento jurídico de aquellos momentos.

En el Informe presentado por la Facultad de Derecho de la Universidad de La Habana en la I Conferencia de Facultades y Escuelas Latinoamericanas de Derecho efectuada en México en el año 1959, se plantea que "el estudio del Derecho en esta Facultad se ha caracterizado por su orden eminentemente doctrinal, siguiendo las tendencias más consagradas universalmente, al que se ha pretendido injertar aspectos de práctica de Derecho,

20 La Cátedra A1-Derecho romano: Dr, Ernesto DiHIGo y Dr. Julio Morales GóMEZ; Cátedra A2-Derecho romano: Dr. Emilio FernÁndez CAMUS; Cátedra B- Derecho civil ( 1 " curso): Dr. José GuERRA LóPEZ; Cátedra C-Derecho civil (2. ${ }^{\circ}$ curso): Dr. Félix MARTíneZ GIRALT; Cátedra D-Derecho civil (3. ${ }^{\circ}$ curso): Alberto Blanco Y SÁNCHEZ; Cátedra El-Derecho procesal civil (1. ${ }^{\circ}$ curso): Pedro CuE ABReU; Cátedra E2-Derecho procesal civil (2. ${ }^{\circ}$ curso) y Derecho procesal criminal: Dr. Alberto DEL JUNCO ANDRE; Cátedra F-Legislación obrera y de la propiedad industrial: Dr. Rodolfo MÉNDEZ PÉNATE; Cátedra G-Derecho penal $\left(1 .^{\circ}\right.$ y $2^{\circ}$ curso): Dr. Guillermo PÓRTELA; Cátedra H-Derecho mercantil $\left(1 .^{\circ}\right.$ y $2^{\circ}$ curso): Dr. Ramón ZAIDYNY MÁrquEZ STERLING; Cátedra I-Derecho hipotecario: Dr. Gustavo TOMEU ADÁN; Cátedra J-Introducción general al estudio del Derecho y Filosofía del Derecho: Dr. Emilio FERnÁnDEZ CAMUS. Vid. Catálogo General. 


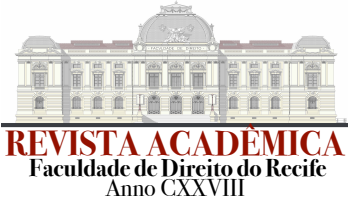

en el siglo pasado, mediante las "Reglas Orgánicas para las Academias teórico-prácticas de Derecho" instituidas por Real Decreto de 10 de agosto de 1886 y, posteriormente, con la introducción de Seminarios para el adiestramiento práctico de los estudiantes y para realizar trabajos de investigación.”(INFORME DE LA FACULTAD DE DERECHO DE LA UNIVERSIDAD DE LA HABANA, 1959, p. 77)

En el propio informe cuando se hace referencia a las sugerencias para mejorar el estado actual de la organización y metodología de la enseñanza e investigación en la propia Facultad, se dejaba claro que debía imponerse "una reestructuración del Plan de estudios a fin de incluir nuevas asignaturas acordes con los tiempos, e intensificar la labor de los Seminarios para que los graduados sean más aptos en el ejercicio profesional, de forma tal que el ejercicio de la carrera no los convierta en meros "prácticos", sino en profesionales cultos y morales. Para ello es imprescindible en el nuevo plan de estudios, incluir disciplinas morales, tan desconocidas por algunos abogados en el ejercicio profesional.”(INFORME DE LA FACULTAD DE DERECHO DE LA UNIVERSIDAD DE LA HABANA, 1959, p. 77)

La situación política del país a finales de la década de los años cincuenta, en especial, la vinculación de los estudiantes universitarios en la lucha contra la dictadura del tristemente célebre general Fulgencio BATISTA provocó que el régimen militar obligara a las universidades de Oriente, Santa Clara y La Habana a cerrar sus puertas y suspender las clases. El 3 de diciembre de 1956 el Consejo Universitario ordena aplazar el reinicio de las clases hasta que existiesen condiciones políticas para el desarrollo normal del curso académico, ratificado el 17 de diciembre, donde se dice que se reanudarían el 7 de enero.

El 13 de marzo de 1957 la policía ocupa la Universidad y el 14 la Federación Estudiantil Universitaria (FEU) lanza las consignas de boicoteo a todo intento de reanudar el curso académico y de asistencia a clases, cerrando así la Universidad sus puertas por poco más de dos años. La enseñanza universitaria continuó impartiéndose en los centros privados creados por toda la isla. 


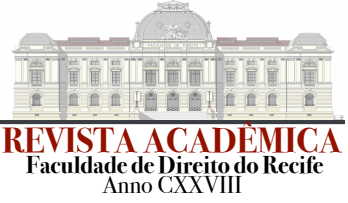

\section{ALGUNAS CONCLUSIONES SOBRE LA ENSEÑANZA DEL DERECHO EN EL PERÍODO CUESTIÓN DE ESTUDIO}

Algunos análisis sobre el tema sostienen que si se quiere caracterizar con grandes rasgos la metodología de la enseñanza desarrollada en la Facultad de Derecho de La Habana anterior al Triunfo revolucionario de 1959, habría que tener presente que se enseñó casi de forma general mediante la clase magistral o conferencia del profesor, que podía terminar con la respuesta a preguntas formuladas durante o al terminar ésta. El nivel de exigencia de conocimientos, era catalogado como desigual, ya que si bien algunos profesores no suspendían en los exámenes a ningún alumno, por ignorante que fuera; otros, por el contrario, eran extraordinariamente severos. A esto hay que sumarle y siguiendo el criterio de RODRÍGUEZ SOLVEIRA que "las autoridades universitarias no intervenían en el grado de exigencia porque el Profesor era "dueño" de su cátedra y decidía sobre contenidos de enseñanza, métodos, nivel de conocimientos, etc.” (INFORME DE LA FACULTAD DE DERECHO DE LA UNIVERSIDAD DE LA HABANA, 1959, p. 77)

Partiendo de lo antes expuesto puede afirmarse que estaban presentes los rasgos de la llamada escuela tradicional que se remonta al siglo XVII y coincide con la ruptura del mandato feudal, el surgimiento de la burguesía y la constitución de los Estados nacionales. En ella el orden y la autoridad vienen a ser las columnas vertebrales de este modelo, donde el papel protagónico está en la enseñanza autoritaria que se centra en el maestro o profesor, dueño del conocimiento y la información, de manera que sólo se le dejaba al estudiante un papel pasivo.

Los rasgos distintivos de la escuela tradicional, según DEL Río HERNÁNDEZ (2011, p. 639-649) y que se evidencian en la etapa que se analiza, son el verticalismo, que sitúa al profesor en una posición jerárquica superior con respecto al alumno, trayendo consigo relaciones de dominio, subordinación y competencia. La dependencia y la sumisión se hacen habituales en la educación diaria, presentándose también de forma significativa el autoritarismo, donde predomina de forma casi absoluta la voz del profesor en la toma de decisiones relacionadas con el proceso. En el último lugar de esta cadena jerárquica se encuentra situado el alumno, carente de poder y sin ejercer influencia en las decisiones. Otra 


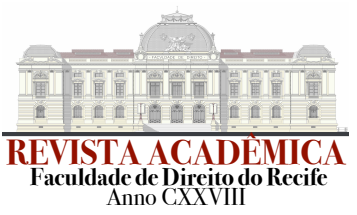

de las características es el verbalismo, donde se privilegia el método expositivo, que queda expresado básicamente a través de conferencias y clases magistrales impartidas por el profesor.

Aquí las lecturas de fuentes directas, la observación y la experimentación quedan excluidas y la ciencia se analiza como algo estático que el alumno debe nombrar, clasificar, describir, pero no cuestionar. El intelectualismo, presente también, sólo ve al alumno como receptor de conocimientos, desempeñando un papel importante la repetición memorística de los contenidos. En el mismo el desarrollo emocional y la formación de valores en el alumno no se tiene en cuenta, por lo que sólo se privilegia la teoría, que de forma evidente queda divorciada de la práctica.

Además de estos rasgos distintivos, y siguiendo el criterio de la citada autora (DEL RÍO HERNÁNDEZ, 2011, p. 39-640), el método tradicional, presente aquí, desconoce el desarrollo afectivo del alumno, favorece la «domesticación», frena el desarrollo social, promueve el formalismo excesivo, la fragmentación de los conocimientos y la súper especialización. Estos rasgos del modelo tradicional moldean los diversos componentes del proceso docente-educativo: los objetivos, los contenidos, las formas, los métodos de enseñanza y la evaluación del aprendizaje. Además, influyen también en el componente investigativo.

Señala además DEL Río HERNÁNDEZ (2011, p. 639-640) que en cuanto a los métodos de enseñanza, el profesor se limita al método expositivo y existe un predominio de la cátedra magistral, la clásica lección y la conferencia, donde el alumno asume el papel de espectador. Se recurre al verbalismo en detrimento de la observación, la experimentación y otros métodos activos. Aquí los medios de enseñanza se reducen prácticamente al uso de notas, textos, láminas y pizarrón.

Es preciso señalar que la evaluación del aprendizaje en este modelo adolece de imprecisiones, abusos y arbitrariedades, sin dejar de mencionar que muchas veces se convierte en un medio más que utiliza el profesor para reforzar el vínculo de dependencia y subordinación de sus alumnos, convirtiéndose esta en lo más parecido a un arma de intimidación y represión. La evaluación viene siendo el punto culminante y objetivo final del proceso de enseñanza a través del cual se miden los conocimientos del alumno. Se convierte 


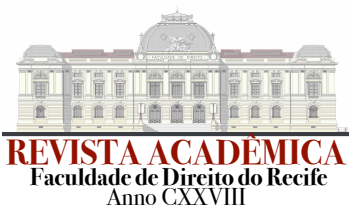

en una actividad mecánica en la que se aplican exámenes y se asignan calificaciones al final del curso. En ella prevalecen los exámenes reproductivos que solo constatan la capacidad repetitiva y memorística del estudiante. Por otra parte, al no estar suficientemente claros los objetivos y ser sumamente amplios los contenidos, la evaluación no está dirigida a alcanzar los propósitos claves, ni los conocimientos.

\section{BIBLIOGRAFÍA}

Armas, Ramón de; TORRES-CUEVAS, Eduardo \& BALLESTER, Ana Cairo: Historia de la Universidad de La Habana. 1728-1978. (2 volúmenes), Editorial de Ciencias Sociales, La Habana, 1964.

ATIENZA, Manuel: ¿Es posible una enseñanza científica del Derecho?, en Revista El Basilisco, No. 5, noviembre-diciembre de 1978.

BÁEZ, Luis y Pedro de la Hoz: "Dos pasiones", en Monseñor Carlos Manuel de Céspedes se confiesa, Casa Editora Abril, 2015.

BETANCOURT, Eduardo López: La enseñanza del Derecho, Sistema de Universidad abierta, Facultad de Derecho, UNAM. Disponible en http://www.derecho.duad.unam.mx/amicuscuriae-english/descargas/10_feb_09/LA_ENSE.pdf

BISBÉ, Manuel: “Ante la tumba de Ramiro Valdés Daussá. La estela ejemplar”. Tomado de: Periódico Luz, La Habana, 17 de agosto de 1940.

BULTÉ, Julio Fernández: “Tras las pistas de la Revolución en 40 años de Derecho", Revista Temas No. 16 y 17, octubre de 1998 - junio de 1999.

: Prólogo al libro de Nancy de la Caridad Ojeda Bermúdez y Teresa Delgado Vergara, "Derecho de Obligaciones, comentarios al Código Civil", Editorial Félix Varela, La Habana, 2001.

Habana, 2005.

: Teoría del Estado y del Derecho (Teoría del Derecho), Editorial Félix Varela, La

Filosofía del Derecho, Editorial Félix Varela, La Habana, 2003.

Historia del Estado y el Derecho en Cuba, Editorial Félix Varela, La Habana, 2004.

"Fernando Álvarez Tabío: el profesor y el jurista", en El Derecho Público en Cuba a comienzos del siglo XXI. Homenaje al Dr. Fernando Álvarez Tabio. Álvarez Tabío Albo, Ana María y AndryMatilla Correa (coordinadores), Editorial UH, La Habana, 2011. 


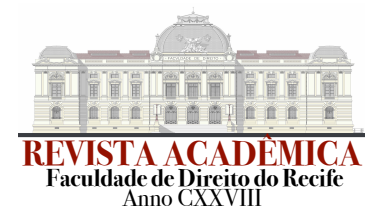

CABRA CAMACHO, Henry: "La Enseñanza del Derecho en América Latina”, ponencia presentada en la III Convención Latinoamericana de Derecho, Universidad de Antioquia, 13-17 de septiembre de 1999. CD de Memorias.

CANTÓN NAVARRO, José: Historia de Cuba, El Desafio del Yugo y la Estrella, Editorial SIMAR S.A., La Habana, 2003.

CARRILLO GARCÍA, Yoel y GARCÍA, Walter Mondelo: "El marxismo jurídico en Cuba. Del voluntarismo ontológico al positivismo ideológico", en "El Derecho público en Cuba a comienzos del Siglo XXI. Homenaje al Dr. Fernando Álvarez Tabio”, Ana María Álvarez Tabío y Andry Matilla Correa (Coordinadores), Editorial UH, 2011.

FIX-ZAMUNDIO, Héctor: "Reflexiones sobre la enseñanza del Derecho en México y Latinoamerica", en Antología de estudios sobre la enseñanza del Derecho, UNAM, 1995, p. 5, consultado en http://biblio.juridicas.unam.mx/libros/1/247/5.pdf.

GUANCHE, Julio César. La imaginación contra la norma. Ocho enfoques sobre la República de 1902. Ediciones La Memoria, Centro Cultural Pablo de la Torriente Brau, La Habana, 2001.

DEVOTO BERRIMAN, Carolina: Enseñar Derecho y preparar futuros abogados, ¿una cuestión metodológica?, en Actas del Primer Congreso Nacional de Pedagogía Universitaria y Didáctica del Derecho, tomado de http://derecho-scl.udd.cl

DEL RÍO HERNÁNDEZ, Mirtha A.: "Influencia de los modelos pedagógicos en la enseñanza y la investigación jurídica en América Latina", en El Derecho como saber cultural. Homenaje al Dr. Delio Carreras Cuevas, coordinado por Andry Matilla Correa, Editorial de Ciencias Sociales y Editorial UH, La Habana, 2011.

DIHIGO Y MESTRE, Juan M. La Universidad de la Habana (1728-1928) Habana: Carasa y Cia, 1930.

ESCASENA, José L.: La evolución de la legalidad en Cuba, Editorial de Ciencias Sociales, La Habana, 1990.

FERNÁNDEZ ESTRADA, Julio Antonio: Derecho, cultura jurídica e identidad nacional en Cuba, en: http://www.sinpermiso.info/textos/derecho-cultura-juridica-e-identidad-nacionalen-cuba, consultado el 7-01-16.)

FIGUEROA, Jose R. H.: Discurso inaugural del Curso Académico de 1925 a 1926. Habana, Imprenta y Papelería de Rambla, Buza y Ca. , 1925.

FLORES GARCÍA, F.: Apuntamientos Sobre la Historia de la Enseñanza Jurídica en México, 1893, en: http//www.bibliojuridica.org/libros/libro.htm?l=700, consultado 26-01-16. 


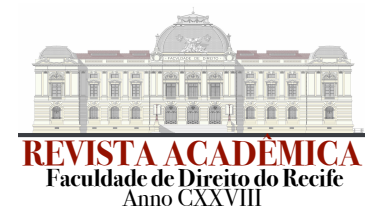

GONZÁLEZ CARBAJAL, Ladislao: El Ala Izquierda Estudiantil y su época, Editorial de Ciencias Sociales, La Habana, 1974.

INFORME DE LA FACULTAD DE DERECHO DE LA UNIVERSIDAD DE LA HABANA recogido en: Memoria de la I Conferencia de Facultades y Escuelas Latinoamericanas de Derecho, 1959, Universidad Nacional Autónoma de México, 1959.

LEÓN COTE, Miguel Ángel: "La Enseñanza del Derecho en Latinoamérica”, ponencia presentada en la III Convención Latinoamericana de Derecho, Universidad de Antioquia, 13-17 de septiembre de 1999. Contenido en CD de memorias.

MARTÍNEZ ALMIRA, Ma. Magdalena: Historia del Derecho. Una reflexión sobre el concepto y el método ante la implementación del Espacio Europeo de Educación Superior. Universidad de Alicante, 2012.

MARTÍ, José: "Abono. La sangre es buen abono". Obras completas, Editorial Nacional de Cuba. La Habana. 1964.

MATILLA CORREA, Andry (coordinador): Panorama de la Ciencia del Derecho en Cuba, Estudios en Homenaje al Dr. Julio Fernández Bulté, Editorial Lleonard Muntaner, Palma, 2009.

(coordinador): Cuestiones histórico-jurídicas. I Jornada Nacional de Historia del Derecho, Editorial UNIJURIS, 2014.

(coordinador): Estudios sobre Historia del Derecho en Cuba, Editorial Ciencias Sociales, La Habana, 2009.

: "Panorama general del Derecho Administrativo en Cuba", en Gonzalez-Varas Ibáñez, Santiago (coordinador), Derecho Administrativo Iberoamericano, 2da edición, Instituto Nacional de Administración Pública, Madrid, 2012, pp. 407 a 508.

\& VÉLEZ, Alie Pérez. Estudios Jurídicos homenaje al profesor doctor Eurípides Valdés Lobán, Ediciones Loynaz, Pinar del Río, 2016.

MESA CASTILLO, Olga: "Participación y staus jurídico-político de las mujeres en la Cuba colonial (1492-1899), en: Matilla Correa, Andry (coordinador): Estudios sobre Historia del Derecho en Cuba, Editorial del Ciencias Sociales, La Habana, 2009, p. 271.

MESA M., Domingo A: "Pluralidad discursiva en la Enseñanza del Derecho: una propuesta para las facultades latinoamericanas", ponencia presentada en la III Convención Latinoamericana de Derecho, Universidad de Antioquia, 13-17 de septiembre de 1999. Recogido en CD de memorias.

MONREAL, Educardo Novoa: "Algunos aspectos sobre contenido de una enseñanza moderna del derecho”. En: Ensayos sobre metodología, docencia e investigación,1981. 


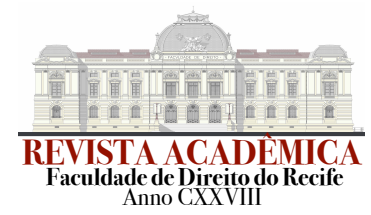

SAAVEDRA, Orlando Naranjo \& ZALDÍVAR, Ricardo: "Estudios de Derecho en Cuba hasta 1959", en Revista Caribeña de Ciencias Sociales, febrero 2013, en: http://caribeña.eumed.net/ estudios-derecho-cuba/

VÉLIZ, Alie Pérez. Aproximación a la Didáctica del Derecho: Historicismo jurídico y métodos problémicos, Editorial Académica española, 2012, p. 29

PLAZAS VEGA, Mauricio: "La Enseñanza del Derecho", ponencia presentada en la III Convención Latinoamericana de Derecho, Universidad de Antioquia, 13-17 de septiembre de 1999. Recogido en CD de memorias.

PRIETO MORALES, Aldo: “Algunas ideas sobre el Derecho a través de la historia", en Revista Cubana de Derecho, Segunda Época, No. 3, Diciembre de 1972.

VARONA, Enrique José. La instrucción pública en Cuba. Su pasado, su presente. Imprenta de Rambla y Bouza, La Habana, 1901 . Las reformas de la enseñanza superior, Tipografía El Fígaro, La Habana, 1900.

VILLA ORREGO, Hernán: “Aprender y desaprender: el reto para una nueva concepción en la Enseñanza del Derecho", ponencia presentada en la III Convención Latinoamericana de Derecho, Universidad de Antioquia, 13-17 de septiembre de 1999. Recogido en CD de memorias.

WITKER, Jorge V. Metodología de la enseñanza del Derecho Porrúa, México, 2008

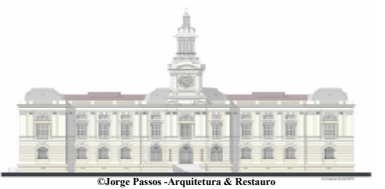

